\title{
Visceral adiposity and renal function: an observational study from SPECT-China
}

\author{
Kun Zhang ${ }^{\dagger}$, Qin Li ${ }^{\dagger}$, Yi Chen, Ningjian Wang and Yingli Lu*
}

\begin{abstract}
Background: Lipid accumulation product (LAP) is a novel and effective index of visceral adiposity distribution based on waist circumference and triglycerides concentration. Few studies investigated the relationship between LAP and eGFR. We aimed to explore whether LAP was associated with declined renal function (eGFR $<60 \mathrm{~mL} / \mathrm{min} /$ $1.73 \mathrm{~m}^{2}$ ), and also whether it exhibited obvious superiority in predicting kidney impairment compared with other obesity indices.

Methods: In this cross-sectional study, 10,012 subjects were recruited from 22 sites in East China. LAP was calculated with the following formula: (WC-65) X TG for males, (WC-58) x TG for females.

Results: $4.7 \%$ participants with declined renal function had a higher LAP quartile. LAP was strongly associated with eGFR level (Beta: -0.073, $P<0.001)$ and declined renal function $(P<0.001)$ even after adjustment for age, sex, smoking, drinking, diabetes and hypertension. The risk of renal dysfunction increased 2.32-fold for the highest quartile LAP relative to the lowest quartile (OR: $2.32,95 \% \mathrm{Cl}: 1.52-3.53, P<0.001)$. LAP exerted the largest area under the curve among different obesity indices (AUC ROC:0.644, 95\%Cl: 0.618-0.670, P < 0.001).
\end{abstract}

Conclusions: Our findings showed that LAP strongly associated with declined renal function and could be one of markers for predicting the risk of renal dysfunction in the general Chinese population.

Trial registration: ChiCTR-ECS-14005052 (WHO international clinical trials register platform in China). Registered 20 July 2014.

Keywords: Visceral adiposity dysfunction, Declined renal function, LAP index

\section{Background}

Chronic kidney disease (CKD) has attracted extensive attention during the past decades as a major challenge for global health. The CKD prevalence rate in the general Chinese population has reached $10.8 \%$ in 2012 [1]. Rapid increase in the CKD prevalence rate will have negative influences on China, including a large economic burden and poor quality of life [2-4]. Early identification and management of CKD is therefore beneficial to control and delay the progression to end-stage renal disease (ESRD) and other cardiovascular events.

Extensive epidemiological studies have indicated that obesity, especially visceral obesity, is involved in the development of chronic kidney disease $[5,6]$ and that an obese

\footnotetext{
* Correspondence: luyingli2008@126.com

${ }^{\dagger}$ Equal contributors

Institute and Department of Endocrinology and Metabolism, Shanghai Ninth People's Hospital, Shanghai Jiao Tong University School of Medicine, No.639 Zhizaoju Road, Shanghai 200011, China
}

phenotype, independent of diabetes and hypertension, predicts a higher risk of CKD [7]. Traditional obesity index of BMI has been widely used in clinical practice, but failed to distinguish lean body mass from adipose tissue limits its application in the assessment of adiposity distribution [8]. Waist circumference (WC) is a more frequently used index of visceral obesity [9]. However, whether waist circumference is associated with declined kidney function is still controversial $[10,11]$. Thus, we sought an appropriate indicator to evaluate the adverse influence of visceral obesity on kidney dysfunction. LAP, as a novel and effective metabolic index, showed promising potential in reflecting visceral adiposity dysfunction. LAP was first proposed by Kahn [12] to predict cardiovascular risk in 2005, which was determined by WC and triglycerides (TG) concentration. Recently, LAP was reported to have strong associations with insulin resistance [13, 14], diabetes [15], NAFLD [16] and even metabolic syndrome [17], all of which were 
associated with CKD [18]. However, there are few studies investigating the relationship between LAP and CKD in the general Chinese population. In addition, despite the significant influences of diabetes and hypertension on renal function, few studies have adjusted for these factors.

Based on the Survey on Prevalence in East China for Metabolic Diseases and Risk Factors (SPECT-China) conducted in 22 sites (Shanghai, Zhejiang, Anhui, Jiangsu and Jiangxi Province) between 2014 and 2015, we aimed to investigate whether LAP is associated with a decline in glomerular filtration rate (eGFR) in East China and then to further explore its ability to predict declined renal function.

\section{Methods}

\section{Participants}

Data are extracted from SPECT-China, a populationbased, cross-sectional survey conducted to investigate the prevalence of metabolic disease and risk factors in East China (Registration number: ChiCTR-ECS14005052, www.chictr.org.cn). A stratified cluster sampling method was performed, as previously reported [19]. Chinese citizens aged over 18 years who had lived at their current residence for 6 months or longer were selected to participate in the study. Those with acute illness, severe communication problems, or who were unwilling to participate were excluded. From January 2014 to December 2015, 10,441 adult subjects were recruited in the SPECT-China study from 22 sites in Shanghai, Zhejiang, Anhui, Jiangsu and Jiangxi Province. We excluded participants with missing values for BMI $(n=257)$ or WC $(n=167)$ or lipid profile $(n=4)$ or eGFR $(n=1)$. Finally, a total number of 10,012 participants ultimately were included in the study to investigate the association between declined renal function and LAP. Informed consent was obtained from all subjects before data collection. The study protocol was approved by the Ethics Committee of Shanghai Ninth People's Hospital, Shanghai JiaoTong University School of Medicine. All procedures followed were in accordance with the ethical standards of the responsible committee on human experimentation (institutional and national) and with the Helsinki Declaration of 1975, as revised in 2008.

\section{Measurements}

Data collection including information about demographic characteristics, medical history and lifestyle risk factors were completed by the same trained physicians and students at every survey site. Height and body weight were measured with subjects wearing light clothing and no shoes. BMI was defined as weight in kilograms divided by height in meters squared. Blood pressure was measured by sphygmomanometer following standard methods as previously described [20]. Neck circumference was performed with the following requirements. Subjects stood upright with their head placed in the Frankfort horizontal plane. The superior edge of the tape measure was placed just below the laryngeal prominence and applied perpendicular to the long axis of the neck. WC was measured midway between the inferior border of the last rib and the crest of the ilium in a horizontal plane. Hip circumference was measured around the pelvis at the point of the maximal protrusion of the buttocks. Smoking was described as having smoked at least 100 cigarettes in one's lifetime and currently smoking cigarettes.

Blood samples were drawn from participants after an overnight fast of $8 \mathrm{~h}$ or longer. Plasma glucose and lipid profiles including fasting plasma glucose, TG, total cholesterol (TC), high density lipoprotein (HDL) and low density lipoprotein (LDL) were measured by BECKMAN COULTER AU 680 (Germany). HbA1c was measured by high-performance liquid chromatography (MQ-2000PT, China).

\section{Definition and calculation}

eGFR was calculated according to the Chronic Kidney Disease-Epidemiology Collaboration (CKD-EPI) equation. Declined renal function was defined as eGFR less than $60 \mathrm{~mL} / \mathrm{min}$ per $1.73 \mathrm{~m}^{2}$. LAP was calculated by the following formula where $\mathrm{WC}$ was expressed in centimeter, TG in mmol/L: (WC-65) x TG for males, (WC-58) x TG for females. Visceral adiposity index (VAI) was calculated according to the formula: (WC/ $(39.68+(1.88 \times \mathrm{xBM}))) \times(\mathrm{TG} / 1.03) \times(1.31 / \mathrm{HDL})$. Body adiposity index (BAI) was calculated as hip circumference in centimeter divided by height in meter18. Diabetes was defined as a fasting plasma glucose of $7 \mathrm{mmol} / \mathrm{L}$ or higher, $\mathrm{HbA} 1 \mathrm{c}$ of $6.5 \%$ or higher, or a previous diagnosis of type 2 diabetes. Hypertension was defined as systolic blood pressure $\geq 140 \mathrm{mmHg}$, diastolic blood pressure $\geq 90 \mathrm{mmHg}$, current use of antihypertensive drug, or self-reported history of hypertension.

\section{Statistical analysis}

Statistical analyses were conducted by using IBM SPSS software, Version 23 (IBM Corporation, Armonk, NY, USA). General characteristics are described as the mean \pm standard deviation (SD) for continuous variables or as a proportion (\%) for categorical variables. To compare characteristics of the participants by LAP quartiles, the one-way ANOVA test was used for continuous variables, and a Chi-square test was used for categorical variables.

The LAP was divided into quartiles. The fourth quartile meant the highest and the first quartile displayed the lowest. The prevalence of declined renal function was calculated in each quartile. We used linear regression analyses to evaluate the association of eGFR with LAP and other obesity indices (BMI, VAI, WC and BAI) in 
three models. Model 1 was unadjusted. Model 2 controls for age, sex, smoking and drinking. Model 3 additionally controls for diabetes and hypertension. LAP and VAI were further log-transformed because of a high skew. Logistic regression was used to investigate the relationship between LAP and declined renal function. The first quartile of LAP served as the reference point. Data were expressed as odds ratios (OR) and 95\% confidence intervals $(\mathrm{CI})$. Adjusted models were the same as those in the linear regression. All of the analyses were two-sided. $P<0.05$ was considered statistically significant.

To investigated the predictive abilities of LAP and other obesity indices for declined renal function, we compared the area under the curve (AUC) of the receiver operating characteristic (ROC) [21]. The differences of AUC between different indices and LAP were compared by Z-tests.

\section{Results}

\section{Characteristics of the participants by quartiles of LAP} quartiles

As presented in Table 1, the LAP quartile ranges were $\leq 13.03,13.04-24.96,24.97-45.62, \geq 45.63$, respectively. According to trend analysis, age, BMI, WC, neck circumference, hip circumference, BAI, TG, TC, LDL as well as the prevalence of hypertension and diabetes showed a doseresponse relationship with LAP (all P for trend $<0.001$ ). As expected, eGFR and HDL were negatively associated with LAP (all P for trend <0.001). Interestingly, this similar association was also observed in the prevalence of smoking and drinking (all P for trend $<0.001$ ).

\section{Prevalence of declined renal function}

Figure 1. showed the prevalence of declined renal function in each LAP quartile. They were $1.2 \%, 2.6 \%, 4.7 \%$ and $5.5 \%$, respectively. As the LAP quartile increased, the prevalence of declined renal function increased, which implied the obvious association of LAP with the prevalence of declined renal function ( $\mathrm{P}$ for trend $<0.001$ ).

\section{Association of LAP and other obesity indices with eGFR}

Table 2. showed the results of the linear regression analysis investigating the association of different obesity indices with eGFR. In the model adjusted for no factors, $\log$-LAP (Beta $=-0.217$ ), BMI (Beta $=-0.152$ ), waist circumference (Beta $=-0.213)$, BAI (Beta $=-0.147)$ and $\log$-VAI (Beta $=-0.136)$ were negatively associated with eGFR (all $P<0.001$ ). After adjustment for age, sex, drinking and smoking, the association of log-LAP, BMI, WC and log-VAI with eGFR weakened but it was still significant (all $P<0.05$ ). When additional adjustment for diabetes and hypertension, this association did not change but failed to further weaken (all $\mathrm{P}<0.05$ ).

\section{Association of LAP with declined renal function}

As presented in Table 3, the results of logistic regression analysis showed that the OR for declined renal function gradually increased across LAP quartiles in

Table 1 Characteristics of study population by quartiles of LAP

\begin{tabular}{|c|c|c|c|c|c|}
\hline \multirow[t]{2}{*}{ LAP value } & Q1 & Q2 & Q3 & Q4 & \multirow{2}{*}{$\begin{array}{l}P \text { for } \\
\text { trend }\end{array}$} \\
\hline & $\leq 13.03$ & $13.04-24.96$ & $24.97-45.62$ & $\geq 45.63$ & \\
\hline Male, \% & 36.4 & 40.5 & 41.0 & 46.8 & $<0.001$ \\
\hline Age, year & $47.38(13.95)$ & $52.98(12.56)$ & $56.41(11.86)$ & $56.61(11.56)$ & $<0.001$ \\
\hline Body mass index, $\mathrm{kg} / \mathrm{m}^{2}$ & $21.45(2.48)$ & $23.79(2.44)$ & $25.41(2.81)$ & $27.43(3.24)$ & $<0.001$ \\
\hline Waist circumference, $\mathrm{cm}$ & $69.35(5.76)$ & $78.29(6.08)$ & $84.08(6.81)$ & $90.52(8.18)$ & $<0.001$ \\
\hline Neck circumference, cm & $31.61(2.98)$ & $33.06(2.91)$ & $34.08(3.86)$ & $35.54(3.57)$ & $<0.001$ \\
\hline Hip circumference, cm & $87.97(5.21)$ & $92.39(5.37)$ & $95.05(6.09)$ & $98.39(6.85)$ & $<0.001$ \\
\hline $\mathrm{eGFR}, \mathrm{mL} / \mathrm{min} / 1.73 \mathrm{~m}^{2}$ & $94.63(14.99)$ & 89. $88(14.59)$ & $86.03(14.91)$ & $85.22(15.16)$ & $<0.001$ \\
\hline Body adiposity index & $25.28(3.60)$ & $27.32(3.64)$ & $28.72(4.20)$ & $29.91(4.86)$ & $<0.001$ \\
\hline Triglycerides, mmol/L & $0.88(0.32)$ & $1.16(0.41)$ & $1.58(0.53)$ & $3.07(2.53)$ & $<0.001$ \\
\hline Cholesterol, mmol/L & $4.75(1.06)$ & $4.98(1.04)$ & $5.30(1.04)$ & $5.59(1.17)$ & $<0.001$ \\
\hline $\mathrm{HDL}, \mathrm{mmol} / \mathrm{L}$ & $1.59(0.32)$ & $1.46(0.30)$ & $1.39(0.30)$ & $1.27(0.27)$ & $<0.001$ \\
\hline $\mathrm{LDL}, \mathrm{mmol} / \mathrm{L}$ & $2.69(0.64)$ & $2.98(0.70)$ & $3.27(0.77)$ & $3.40(0.81)$ & $<0.001$ \\
\hline Hypertension, \% & 23.9 & 40.0 & 54.4 & 66.4 & $<0.001$ \\
\hline Diabetes, \% & 4.9 & 8.9 & 13.8 & 26.3 & $<0.001$ \\
\hline Smoker, \% & 82.7 & 80.2 & 78.4 & 73.8 & $<0.001$ \\
\hline Drinker, \% & 91.2 & 87.1 & 85.4 & 84.0 & $<0.001$ \\
\hline
\end{tabular}




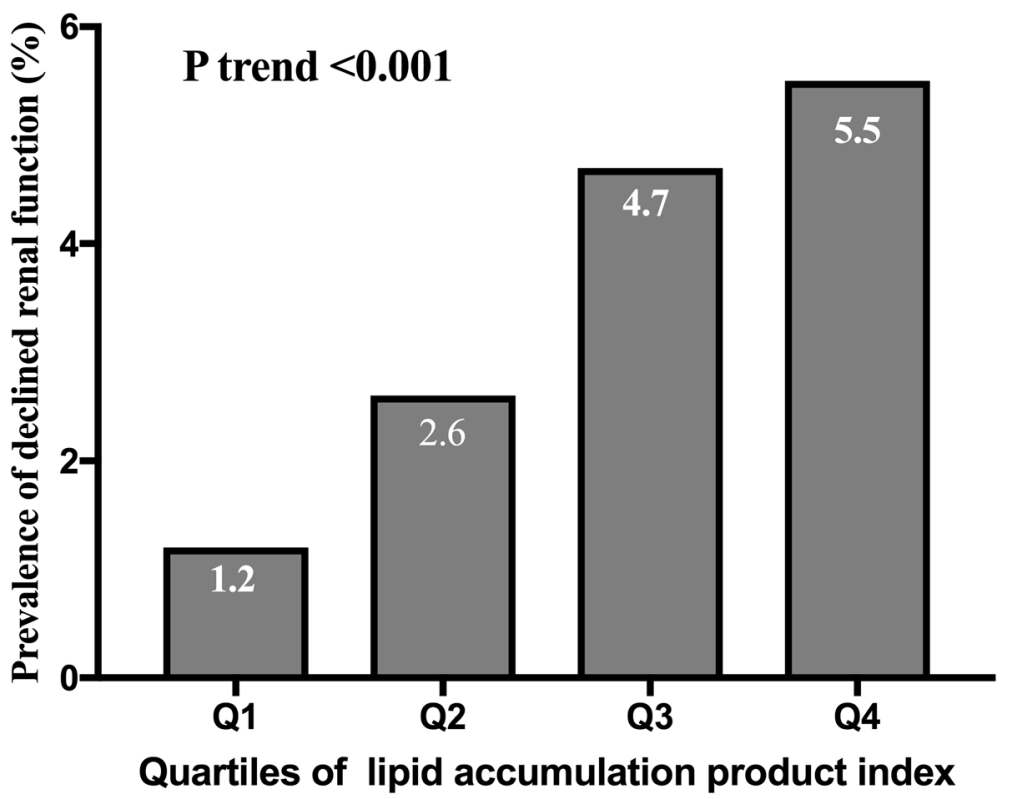

Fig. 1 The prevalence of declined renal function in each quartile of LAP

each model (all $P<0.001$ ). In the unadjusted model (Model 1), the OR of declined renal function in the highest LAP was 4.62 (95\% CI 3.12, 6.85; P < 0.001) compared with the lowest one. After adjustment for age, sex, drinking and smoking, LAP was still significantly associated with declined renal function but this interaction weakened (Model 2). With additional adjustment for diabetes and hypertension, this association did not change and the OR of declined renal function further deceased (Model 3).

\section{AUCs of LAP and other obesity indices to predict declined renal function}

As presented in Table 4, we investigated the predictive abilities of LAP and other obesity indices for declined renal function. The AUC value of LAP was 0.644 (95\% CI: 0.618-0.670). VAI, BAI, WC and BMI were inferior

Table 2 Association of eGFR with different obesity indices

\begin{tabular}{llll}
\hline \multirow{2}{*}{$\begin{array}{l}\text { Independent } \\
\text { variable }\end{array}$} & \multicolumn{2}{l}{ eGFR (Dependent variable) } \\
\cline { 2 - 4 } & Model 1 & Model 2 & Model 3 \\
\hline Log-LAP & $-0.217(0.157)^{* *}$ & $-0.067(0.138)^{* *}$ & $-0.073(0.144)^{* *}$ \\
BMI & $-0.152(0.043)^{* *}$ & $-0.071(0.036)^{* *}$ & $-0.075(0.038)^{* *}$ \\
WC & $-0.213(0.015)^{* *}$ & $-0.030(0.014)^{*}$ & $-0.033(0.014)^{*}$ \\
BAl & $-0.147(0.034)^{* *}$ & $-0.007(0.033)$ & $-0.006(0.034)$ \\
Log-VAl & $-0.136(0.512)^{* *}$ & $-0.064(0.429)^{* *}$ & $-0.069(0.442)^{* *}$
\end{tabular}

The data from linear regression analysis are expressed as Beta coefficients (standard errors). ${ }^{*} P<0.05,{ }^{* *} P<0.001$. Model 1 was unadjusted. Model 2 controls for age, sex, smoking and drinking. Model 3 additionally controls for diabetes and hypertension. VAI and LAP were log-transformed because of their skewed distribution to LAP in AUC value. The BMI showed the lowest AUC value for declined renal function (Fig. 2).

\section{Discussion}

In this large cross-sectional study, we explored the association between LAP and declined renal function in East China. We found that LAP, like other obesity indices, was strongly associated with eGFR level and declined renal function even after adjustment for age, sex, smoking, drinking, diabetes and hypertension. The full-adjusted risk of declined renal function grew by 2.32 times for the highest LAP quartile relative to the lowest quartile. LAP showed a more promising predictive ability for declined renal function compared to other obesity indices. To the best of our knowledge, this is the first large populationbased study to directly compare LAP and the risk of declined renal function in East China.

LAP, which is determined by two components of WC and TG concentration, was first proposed by Kahn in 2005

Table 3 Association of LAP with declined renal function (eGFR $<60 \mathrm{~mL} / \mathrm{min} / 1.73 \mathrm{~m}^{2}$ )

\begin{tabular}{|c|c|c|c|}
\hline LAP value & Model 1 & Model 2 & Model 3 \\
\hline Q1 $(\leq 13.03)$ & 1.0(ref.) & 1.0(ref.) & 1.0(ref.) \\
\hline Q2 (13.04-24.96) & $2.09(1.36,3.22)$ & $1.50(0.96,2.34)$ & $1.45(0.93,2.27)$ \\
\hline Q3 (24.97-45.62) & $3.95(2.65,5.89)$ & $2.20(1.45,3.33)$ & $2.04(1.34,3.09)$ \\
\hline Q4 ( $\geq 45.63)$ & $4.62(3.12,6.85)$ & $2.61(1.74,3.93)$ & $2.32(1.52,3.53)$ \\
\hline$P$ value for trend & $<0.001$ & $<0.001$ & $<0.001$ \\
\hline
\end{tabular}

The data from logistic regression analysis are expressed as odds ratio $(95 \% \mathrm{Cl})$ unless otherwise indicated. Model 1 was unadjusted, Model 2 controls for age (continuous variable), sex, smoking, and drinking. Model 3 additionally controls for diabetes and hypertension 
Table 4 AUCs of LAP and other obesity indices to predict declined renal function

\begin{tabular}{llll}
\hline Index & AUC ROC & $P$ value1 & $P$ value2 \\
\hline LAP & $0.644(0.618,0.670)$ & $<0.001$ & \\
VAl & $0.621(0.594,0.647)$ & $<0.001$ & $<0.001$ \\
BAl & $0.578(0.546,0.609)$ & $<0.001$ & $<0.001$ \\
BMl & $0.574(0.543,0.605)$ & $<0.001$ & $<0.001$ \\
WC & $0.616(0.588,0.645)$ & $<0.001$ & $<0.001$ \\
\hline
\end{tabular}

AUC area under the curve, $R O C$ receiver operating characteristic. $P$ value 1 : the diagnostic value for ROC, two tail significance. $P$ value 2 : the comparisons of AUC between LAP and other obesity indices (Z-test)

to predict cardiovascular outcomes and mortality [12]. Epidemiologic studies further demonstrated that LAP could reflect visceral adiposity dysfunction and be associated strongly with dyslipidemia, insulin resistance, diabetes, PCOS and even metabolic syndrome [22-24]. In our study, we observed that, with the increase of the LAP quartiles, the eGFR level decreased and the prevalence of declined renal function increased. This significant trend was independent of age, sex, smoking, drinking, diabetes and hypertension, which implied that LAP may be a useful tool to identify the risk of declined renal function; we supplemented important evidence to the application of LAP.

Obesity and CKD are closely related, which is consistent with our findings. Chang and his colleagues discovered that the obese phenotype in metabolically healthy obese subjects could suffer from a higher risk for incident CKD
[7], suggesting that obesity per se contributed to renal dysfunction and structural damage independent of metabolic abnormalities. In turn, the protective effect of weight loss on CKD is rather outstanding. Lifestyle intervention including caloric restriction and enhanced physical activity reduced the risk of CKD by $30 \%$ in overweight or obese diabetic patients compared to controls receiving an education intervention [25]. Weight reduction also helped improve obese CKD patients blood pressure, glomerular hyper-filtration and proteinuria [26]. Functional food often was added into regular pharmacological treatment to improve dyslipidemia and decrease the incidence of cardiovascular events, which was perhaps associated with the functional food's anti-inflammatory effects [27]. These findings provided an option of weight reduction, functional food and ACE inhibition interventions in the treatment of overweight or obese patients with CKD [27, 28]. Athrough many findings were reported, the mechanism of how obesity initiated and exacerbated CKD was still not clarified. Recent studies revealed that renal compensatory hyper-filtration was likely to meet the enhanced metabolic demands of the excess weight. The continuous increase in intra-glomerular pressure would damage the kidney structure and increase the risk of advanced kidney disease [29, 30]. In an obese population, adipose tissue would result in release of inflammatory cytokines such as interleukin- 6 or tumor necrosis factor- $\alpha$ to exacerbate kidney injury [31]. Visceral adipose tissue played key roles in the regulation of

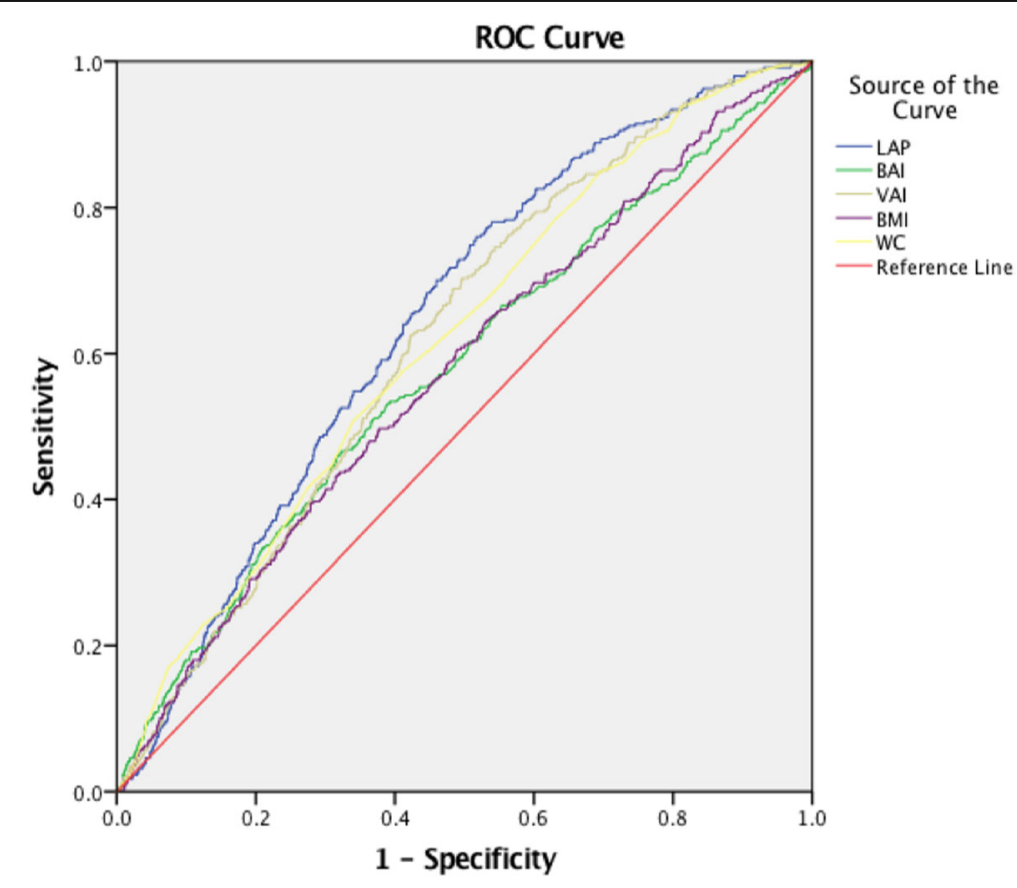

Fig. 2 The association between LAP and declined renal function. In our study, we found that LAP was strongly associated with declined renal function. LAP has the largest area under curves among these five obesity indices, suggesting LAP can be a promosing predictive index for declined renal function 
numerous adipokines and cytokines [32]. Clinical and animals studies demonstrated that ectopic lipid accumulation in the kidney contributed to obesity-related kidney injury [33-35]. Visceral adipose tissue was recognized as pathogenic fat deposition, and this deposition was associated more strongly with metabolic risk factors than the subcutaneous adipose tissue [36]. Our results supported those studies in that visceral adiposity dysfunction, which could be mirrored by LAP, was an independent risk factor for renal dysfunction.

There are several strengths in our study. First, the clinical meaning of this study is significant. Weight reduction helps alleviate the progression of CKD because obesity can be treated and controlled. Second, because the SPECT-China survey is a large population-based cross-sectional study, our results are more representative compared to a clinic-based population. Third, all the anthropometric measurements and biomedical analysis in this survey study were conducted by the same trained physician and students; thus, effective quality control was guaranteed. There are also some limitations in this study. First, because this is a cross-sectional study, we cannot determine a causal relationship between LAP and declined renal function. Second, the post-hoc analysis could be another limitation of this study. All the analyses between LAP and declined renal function were performed with existing data in an exploratory manner. Third, the most of participants enrolled in the study were Chinese residents, but LAP was firstly proposed and calculated based on white population. However, the application of LAP in a Chinese population had been reported in many diseases of insulin resistance, diabetes, NAFLD and even metabolic syndrome.

\section{Conclusions}

Our results demonstrated that LAP was strongly associated with eGFR and the prevalence of declined renal function in East China. LAP could be a promising predictive index for the risk of declined renal function, which was independent of age, sex, smoking, drinking, diabetes and hypertension. Future research should focus on the underlying mechanism.

\footnotetext{
Abbreviations

BAl: Body adiposity index; BMI: Body mass index; FBG: Fasting blood glucose; HbA1c: Glycated hemoglobin; HDL: High density lipoprotein; LAP: Lipid accumulation product; LDL: Low density lipoprotein; VAl: Visceral adiposity index; WC: Waist circumference
}

\section{Acknowledgments}

This study was supported by funding from the National Natural Science Foundation of China $(81270885,81570726)$, the Shanghai Jiao Tong University School of Medicine (2014), the Ministry of Science and Technology in China (2012CB524906) and the Science and Technology Commission of Shanghai Municipality (14495810700, 16410723200), Three-year Action Plan For Public Health System Construction in Shanghai by Shanghai Municipal Commission of Health and Family Planning (2015-2017), and the National Natural Science Foundation of China (81400796).
Availability of data and materials

Not applicable.

\section{Authors' contributions}

Yingli Lu designed the study. Kun Zhang and Qin Li analyzed all data. Kun Zhang drafted the manuscript. Yi Chen and Ningjian Wang provided statistical advice and contributed to the data analysis. Yingli Lu helped revise the manuscript. All authors read and approved the final manuscript.

\section{Ethics approval and consent to participate}

The study protocol was approved by the Ethics Committee of Shanghai Ninth People's Hospital, Shanghai JiaoTong University School of Medicine. Informed consent was obtained from all subjects.

\section{Consent for publication}

Not applicable.

\section{Competing interests}

The authors all declare no financial or other potential conflicts of interest.

\section{Publisher's Note}

Springer Nature remains neutral with regard to jurisdictional claims in published maps and institutional affiliations.

Received: 8 June 2017 Accepted: 20 October 2017

Published online: 27 October 2017

\section{References}

1. Zhang L, Wang F, Wang L, Wang W, Liu B, Liu J, Chen M, He Q, Liao Y, Yu X, et al. Prevalence of chronic kidney disease in China: a cross-sectional survey. Lancet. 2012;379(9818):815-22.

2. Ayodele OE, Alebiosu CO. Burden of chronic kidney disease: an international perspective. Adv Chronic Kidney Dis. 2010;17(3):215-24.

3. Go AS, Chertow GM, Fan D, McCulloch CE, Hsu CY. Chronic kidney disease and the risks of death, cardiovascular events, and hospitalization. N Engl J Med. 2004;351(13):1296-305.

4. Nugent RA, Fathima SF, Feigl AB, Chyung D. The burden of chronic kidney disease on developing nations: a 21st century challenge in global health. Nephron Clin Pract. 2011;118(3):C269-77.

5. Chung HF, Al Mamun A, Huang MC, Long KZ, Huang YF, Shin SJ, Hwang SJ, Hsu CC. Obesity, weight change, and chronic kidney disease in patients with type 2 diabetes mellitus: a longitudinal study in Taiwan. J Diabetes. 2016;9(11):983-93.

6. Mottaghi A, Mirmiran P, Delshad H, Azizi F. Effect of different obesity phenotypes on incidence of chronic kidney disease in Tehranian adults. J Am Coll Nutr. 2016;35(7):587-96.

7. Chang Y, Ryu S, Choi Y, Zhang Y, Cho J, Kwon MJ, Hyun YY, Lee KB, Kim H, Jung $\mathrm{HS}$, et al. Metabolically healthy obesity and development of chronic kidney disease: a cohort study. Ann Intern Med. 2016;164(5):305-12.

8. Frankenfield DC, Rowe WA, Cooney RN, Smith JS, Becker D. Limits of body mass index to detect obesity and predict body composition. Nutrition. 2001;17(1):26-30.

9. Miyatake N, Shikata K, Makino H, Numata T. Decreasing abdominal circumference is associated with improving estimated glomerular filtration rate (eGFR) with lifestyle modification in Japanese men: a pilot study. Acta Med Okayama. 2011;65(6):363-7.

10. Sezer S, Karakan S, Acar NO. Association of conicity index and renal progression in pre-dialysis chronic kidney disease. Ren Fail. 2012;34(2):165-70.

11. Kitiyakara C, Yamwong S, Cheepudomwit S, Domrongkitchaiporn S, Unkurapinun N, Pakpeankitvatana V, Sritara P. The metabolic syndrome and chronic kidney disease in a southeast Asian cohort. Kidney Int. 2007;71(7): 693-700.

12. Kahn HS. The "lipid accumulation product" performs better than the body mass index for recognizing cardiovascular risk: a population-based comparison. BMC Cardiovasc Disord. 2005;5:26.

13. Godinjak A, Godinjak Z, Burekovic A, Surkovic I, Dizdarevic-Bostandzic A Velija-Asimi Z. Insulin resistance and lipid accumulation product in corelation to body mass index in women with polycystic ovary syndrome. Med Arch. 2012;66(6):409-11. 
14. Xia C, Li R, Zhang S, Gong L, Ren W, Wang Z, Li Q. Lipid accumulation product is a powerful index for recognizing insulin resistance in non-diabetic individuals. Eur J Clin Nutr. 2012;66(9):1035-8.

15. Bozorgmanesh M, Hadaegh F, Azizi F. Diabetes prediction, lipid accumulation product, and adiposity measures; 6-year follow-up: Tehran lipid and glucose study. Lipids Health Dis. 2010;9:45.

16. Kim JH, Kwon SY, Lee SW, Lee CH. Validation of fatty liver index and lipid accumulation product for predicting fatty liver in Korean population. Liver Int. 2011;31(10):1600-1

17. Motamed N, Razmjou S, Hemmasi G, Maadi M, Zamani F. Lipid accumulation product and metabolic syndrome: a population-based study in northern Iran. Amol J Endocrinol Invest. 2016;39(4):375-82.

18. Maleki A, Montazeri M, Rashidi N, Montazeri M, Yousefi-Abdolmaleki E. Metabolic syndrome and its components associated with chronic kidney disease. J Res Med Sci. 2015;20(5):465-9.

19. Wang N, Wang X, Han B, Li Q, Chen Y, Zhu C, Chen Y, Xia F, Cang Z, Zhu C, et al. Is exposure to famine in childhood and economic development in adulthood associated with diabetes? J Clin Endocrinol Metab. 2015; 100(12):4514-23.

20. Xu Y, Wang L, He J, Bi Y, Li M, Wang T, Wang L, Jiang Y, Dai M, Lu J, et al. Prevalence and control of diabetes in Chinese adults. JAMA. 2013; 310(9):948-59.

21. Hanley JA, McNeil BJ. The meaning and use of the area under a receiver operating characteristic (ROC) curve. Radiology. 1982;143(1): 29-36.

22. Bozic-Antic I, llic D, Bjekic-Macut J, Bogavac T, Vojnovic-Milutinovic D, Kastratovic-Kotlica B, Milic N, Stanojlovic O, Andric Z, Macut D. Lipid accumulation product as a marker of cardiometabolic susceptibility in women with different phenotypes of polycystic ovary syndrome. Eur J Endocrinol. 2016;175(6):551-60.

23. Macut D, Tziomalos K, Bozic-Antic I, Bjekic-Macut J, Katsikis I, Papadakis E, Andric Z, Panidis D. Non-alcoholic fatty liver disease is associated with insulin resistance and lipid accumulation product in women with polycystic ovary syndrome. Hum Reprod. 2016;31(6): 1347-53.

24. Wakabayashi I, Daimon T. A strong association between lipid accumulation product and diabetes mellitus in japanese women and men. J Atheroscler Thromb. 2014:21(3):282-8.

25. Look ARG, Wing RR, Bolin P, Brancati FL, Bray GA, Clark JM, Coday M, Crow RS, Curtis JM, Egan CM, et al. Cardiovascular effects of intensive lifestyle intervention in type 2 diabetes. N Engl J Med. 2013;369(2): 145-54.

26. Bolignano D, Zoccali C. Effects of weight loss on renal function in obese CKD patients: a systematic review. Nephrol Dial Transplant. 2013; 28(Suppl 4):iv82-98.

27. Pietro S, Matteo C, Maria M, Pietro AM, Maria LM, Salvatore N, Pasquale $P$, Pier SS, Roberto P, Ciccone MM. Nutraceuticals and dyslipidaemia: beyond the common therapeutics. J Funct Foods. 2014;6:11-32.

28. Mallamaci F, Ruggenenti P, Perna A, Leonardis D, Tripepi R, Tripepi G, Remuzzi G, Zoccali C, Group RS. ACE inhibition is renoprotective among obese patients with proteinuria. J Am Soc Nephrol. 2011;22(6): 1122-8.

29. Knight SF, Quigley JE, Yuan J, Roy SS, Elmarakby A, Imig JD. Endothelial dysfunction and the development of renal injury in spontaneously hypertensive rats fed a high-fat diet. Hypertension. 2008;51(2):352-9.

30. Henegar JR, Bigler SA, Henegar LK, Tyagi SC, Hall JE. Functional and structural changes in the kidney in the early stages of obesity. J Am Soc Nephrol. 2001;12(6):1211-7.

31. Bavbek N, Isik B, Kargili A, Uz E, Uz B, Kanbay M, Turgut F, Karakurt F, Akcay A. Association of obesity with inflammation in occult chronic kidney disease. J Nephrol. 2008;21(5):761-7.

32. Ibrahim MM. Subcutaneous and visceral adipose tissue: structural and functional differences. Obes Rev. 2010;11(1):11-8.

33. de Vries AP, Ruggenenti P, Ruan XZ, Praga M, Cruzado JM, Bajema IM, D'Agati VD, Lamb HJ, Pongrac Barlovic D, Hojs R, et al. Fatty kidney: emerging role of ectopic lipid in obesity-related renal disease. Lancet Diabetes Endocrinol. 2014;2(5):417-26.

34. Foster MC, Hwang SJ, Porter SA, Massaro JM, Hoffmann U, Fox CS. Fatty kidney, hypertension, and chronic kidney disease: the Framingham heart study. Hypertension. 2011;58(5):784-90.
35. Yin QH, Zhang R, Li L, Wang YT, Liu JP, Zhang J, Bai L, Cheng JQ, Fu P, Liu F. Exendin-4 ameliorates lipotoxicity-induced Glomerular endothelial cell injury by improving $A B C$ transporter $A 1$-mediated cholesterol efflux in diabetic apoE knockout mice. J Biol Chem. 2016;291(51):26487-501.

36. Porter SA, Massaro JM, Hoffmann U, Vasan RS, O'Donnel CJ, Fox CS. Abdominal subcutaneous adipose tissue: a protective fat depot? Diabetes Care. 2009;32(6):1068-75.

\section{Submit your next manuscript to BioMed Central and we will help you at every step:}

- We accept pre-submission inquiries

- Our selector tool helps you to find the most relevant journal

- We provide round the clock customer support

- Convenient online submission

- Thorough peer review

- Inclusion in PubMed and all major indexing services

- Maximum visibility for your research

Submit your manuscript at www.biomedcentral.com/submit
Biomed Central 